\title{
RC Beams Strengthened with GFrP Plates. I: EXPERIMENTAL STUDY
}

\author{
By Hamid Saadatmanesh, ${ }^{1}$ Associate Member, ASCE, and \\ Mohammad R. Ehsani, ${ }^{2}$ Member, ASCE
}

\begin{abstract}
The static strength of reinforced concrete beams strengthened by gluing glass-fiber-reinforced-plastic (GFRP) plates to their tension flanges is experimentally investigated. Five rectangular bcams and onc T-beam were tested to failure under four-point bending. The measured load versus strain in GFRP plate, steel rebar, extreme compression fiber of concrete. and the load versus deflection for the scction at midspan of the beams are plotted and compared to the predicted values. The results indicate that the flexural strength of RC beams can be significantly increased by gluing GFRP plates to the tension face. In addition, the cpoxy bonded plates improved the cracking behavior of the beams by delaying the formation of visible cracks and reducing crack widths at higher load levels.
\end{abstract}

\section{INTRODUCTION}

According to the statistics of the Federal Highway Administration, more than $40 \%$ of the highway bridges in the United States are in need of replacement or rehabilitation ("Highway" 1989). In addition, many of these bridges were designed for lower traffic volumes and lighter loads than are common today. Therefore, rehabilitation alone will not bring these bridges up to current standards-strengthening and deck widening must also be considered.

External posttensioning has been successfully used to increase the strength of girders in existing bridges and buildings (Klaiber et al. 1982; Saadatmanesh et al. 1989a, 1989b, 1989c). However, this method has several practical difficulties such as providing anchorage for the posttensioning strands, maintaining the lateral stability of the girders during posttensioning, and protecting the exposed strands against corrosion.

Epoxy-bonded steel plate has been used effectively in Europe, South Africa, and Japan to increase the load-carrying capacity of existing concrete bridge girders (Dussek 1980; Klaiber et al. 1987). This strengthening method has been found by practitioners to be economical and efficient to apply. The principles of this technique are fairly simple. Steel plates are epoxybonded to the tension flange, increasing the strength and stiffness of the girder. The advantages of this structural system include the ease of application and the elimination of special anchorages needed in the posttensioning method. Strengthening can be performed while the structure is in use, and it does not reduce the overhead clearance. A shortcoming of this method, however, is the danger of corrosion at the epoxy-steel interface, which adversely affects the bond strength.

To eliminate the corrosion problem, the steel plate can be replaced with

${ }^{1}$ Asst. Prof., Dept. of Civ. Engrg. and Engrg. Mech., Univ. of Arizona, Tucson, AZ 85721 .

${ }^{2}$ Assoc. Prof., Dept. of Civ. Engrg, and Engrg. Mech., Univ. of Arizona, Tucson, AZ.

Note. Discussion open until April 1, 1992. Separate discussions should be submitted for the individual papers in this symposium. To extend the closing date one month, a written request must be filed with the ASCE Manager of Journals. The manuscript for this paper was submitted for review and possible publication on May 4,1990 . This paper is part of the Journal of Structural Engineering, Vol. 117, No. 11, November, 1991. CASCE, ISSN 0733-9445/91/0011-3417/\$1.00 + \$.15 per page. Paper No. 26385. 
a corrosion-proof fiber composite plate. In addition to corrosion resistance, many fiber composites have tensile and fatigue strengths that exceed those of steel. More benefits can also result by externally prestressing the girders at the time of strengthening. The prestressing is accomplished by cambering the girders by means of hydraulic jacks while in loose contact with an epoxycoated composite plate, as shown in Fig. 1(a). The jacks are removed when the epoxy has cured [Fig. 1(b)]. The composite plate, placed in tension, prevents a complete elastic return of the girder. This results in initial compression and tension stresses in the tension and compression faces of the girder, respectively, which oppose stresses induced by gravity loads. The elimination of anchorages in this prestressing scheme results in ease and speed of construction and prevents high, localized stresses in the anchorage zones.

This paper discusses the test results of concrete girders strengthened with epoxy-bonded glass-fiber-reinforced-plastic (GFRP) plates.

\section{Previous Studies}

Several studies of concrete beams strengthened with epoxy-bonded steel plates have been reported in the literature.

MacDonald and Calder (1982) studied the behavior of concrete beams externally reinforced with steel plates bonded to their tension flanges. They tested a series of $3.5-\mathrm{m}$-long (11.5-ft) and 4.9-m-long (16-ft) beams in fourpoint bending. Results showed that full composite action was provided by the adhesive and that significant improvements in performance could be achieved in terms of ultimate load, crack control, and stiffness. Exposure tests were carried out on $0.5-\mathrm{m}$ unreinforced concrete beams with steel plates bonded to one face. Results showed that significant amounts of corrosion of steel plate may take place during natural exposure. Also, a loss in bond strength at the steel-epoxy interface was observed, resulting from the cor-
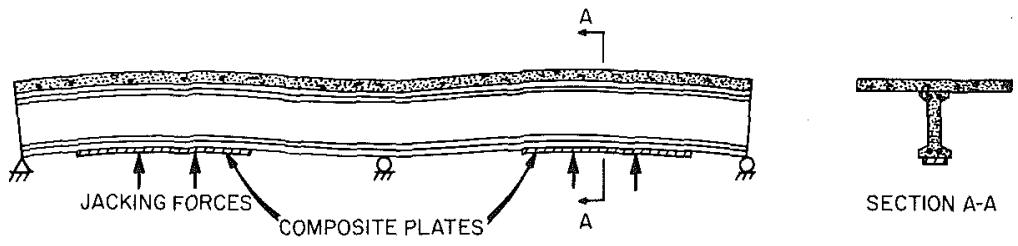

SECTION A-A

a)
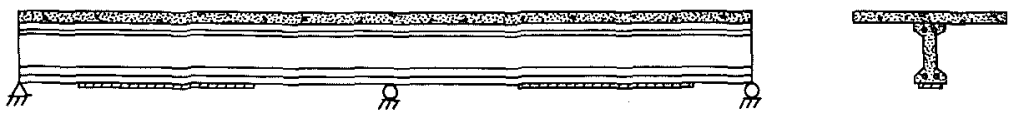

b)

FIG. 1. External Prestressing of Two-Span Continuous Girder: (a) Camber by Jacking; (b) Remove Jacks when Epoxy is Cured 
rosion of the steel plate. The reduction in the overall strength of the exposed beams was attributed to the corrosion.

VanGemert and VandenBosch (1985) reported the results of durability tests on concrete beams with epoxy-bonded external steel reinforcements. They studied the effects of long-term exposure, fatigue, and temperature loading, concluding that the effects of atmospheric corrosion depend for the greater part on the preparation of concrete and steel-plate surfaces and on the workmanship of the repair crew. Therefore, more specialized personnel and a careful control of the preparation work will be necessary. Cyclic loading tests were performed on two beams with spans of $6 \mathrm{~m} \mathrm{(19.7}$ $\mathrm{ft})$ each. The beams were reinforced with a double layer of glued steel plates. The cross section of the beams was $300 \times 250 \mathrm{~mm}(11.8 \times 9.8 \mathrm{in}$.); the steel plates were $5 \mathrm{~mm}$ thick $(0.2$ in.) by (7.9 in.) $200 \mathrm{~mm}$ wide. The beams were tested under four-point bending, and they were subjected to cyclic loads resulting in a maximum stress of $40 \mathrm{~N} / \mathrm{mm}^{2}(5.8 \mathrm{ksi})$. The loading frequency was 30 cycles/min, and 500,000 cycles of load were applied to each beam. The fatigue tests showed that no redistribution of stresses took place by deformation in the glue or by any failure of the glued connection. Also, full-scale temperature loading tests in the temperature tange from $-20^{\circ} \mathrm{C}$ to $+90^{\circ} \mathrm{C}$ were conducted on specimens glued with EPICOL U epoxy adhesive. It was found that the cold-hardening epoxy glue had a poor thermal resistance. There was no decrease of the ultimate load for lower temperatures. However, at higher temperatures, the situation was different. At a temperature of about $60^{\circ} \mathrm{C}$, the glue started to become weaker and more deformable. At lower temperatures, the crack always started at the end of the plate and moved into the concrete. At higher temperatures, the epoxy joint was not able to transfer the shearing stresses from the steel plate to the concrete, and a crack propagated through the epoxy joint, starting at the plate end. The performance of the epoxy joint was strongly reduced at high temperatures.

Swamy et al. (1987) investigated the effect of glued steel plates on the first cracking load, cracking behavior, deformation, serviceability, and ultimate strength of reinforced concrete beams. Twenty-four beams were tested. Each beam had a rectangular cross section of $155 \times 255 \mathrm{~mm}(6.1$ $\times 10$ in.) and was $2.5 \mathrm{~m}$ long $(8.2 \mathrm{ft})$. The beams were reinforced with three 20 -mm-diameter $(0.79$, in.) bars at an effective depth of $220 \mathrm{~mm}(8.7$ in.). Three glue thicknesses, $1.5 \mathrm{~mm}(0.06 \mathrm{in}),. 3 \mathrm{~mm}(0.12 \mathrm{in}$.), and $6 \mathrm{~mm}$ (0.24 in.) were used. For each glue thickness, three plate thicknesses were used: $1.5 \mathrm{~mm}$ (0.06 in.), $3 \mathrm{~mm}$ (0.17 in.), and $6 \mathrm{~mm}$ (0.24 in.), all of constant width of $125 \mathrm{~mm}$ (4.9 in.). For comparison, several beams were tested with lap plates, double plates, and variable thickness for the glue along the length of the beam. The adhesive thickness varied from $3 \mathrm{~mm}$ to $8 \mathrm{~mm}(0.12$ to 0.31 in.). The results indicated that the addition of glued steel plates to a reinforced concrete beam can substantially increase the flexural stiffness, reduce cracking and structural deformations at all load levels, and contribute to the ultimate flexural capacity. The net effect of the reduced structural deformations was that the serviceability loads were substantially increased by the stiffening action of the glued plates. Lapped plates, precracking prior to plating, variable glue thickness, and the presence of stress concentrations in the adhesive all had no adverse effect on the structural behavior of the plated beams.

Other reports, i.e., by Raithby (1980) and Lloyd et al. (1982), can also be found in the literature. These reports discuss various aspects of the 
behavior of concrete beams externally reinforced with epoxy-bonded steel plates.

There are also several field applications of epoxy-bonded steel plates to concrete beams. The first recorded case was in Durban, South Africa, in 1964, where epoxy-bonded steel plates were used to strengthen concrete beams in an apartment complex (Dussek 1980), where part of the reinforcing steel in the building had been accidentally omitted during the construction.

Four bridges on the M5 Motorway at Quinton Interchange, Worcestershire, and two bridges on the M25-M20 Motorway Interchange at Swanley, Kent, in England were strengthened by plating in 1975 and 1977, respectively (Dussek 1980). At Quinton, cracks were discovered in the soffits of the end and main spans during the routine inspection of the bridges. These bridges were constructed of box-reinforced concrete slabs, and they were continuous over three spans of $16.75 \mathrm{~m}, 27.4 \mathrm{~m}$, and $16.75 \mathrm{~m}(55,90$, and $55 \mathrm{ft})$. Calculations indicated that inadequate tension reinforcement had originally been provided in parts of the end spans and in the edge of the main spans. Two alternative repair methods were considered: (1) Prestressing with cables; and (2) bonding steel plates. Prestressing with cables was rejected for three reasons: (1) Although the deck construction was of box design, a very considerable force would be required to stress the concrete effectively; (2) it would be difficult to establish suitable anchorages in the slab soffits; and (3) overhead clearance would be adversely affected. Therefore, all bridges were repaired by plating.

Epoxy-bonded steel plates were used to strengthen several buildings in Switzerland ("Araldit" 1979). In a building in Zurich, additional live load had to be carried on reinforced concrete floor slabs and supporting reinforced concrete beams. The flexural strength of the structure was upgraded by plating. In addition, steel plates also were bonded to the sides of the beams to help carry the additional live-load shear. This method also was used to strengthen a critical foundation of a building and to strengthen the industrial floor of a factory.

There are other reported applications of epoxy-bonded steel plates to concrete girders (Klaiber et al. 1987). They all attest to the effectiveness of this technique for retrofitting concrete girders in existing structures.

\section{Fiber-REINForced Composites}

Fiber composites and reinforced plastics offer unique advantages in many applications where conventional materials cannot provide satisfactory service life. The high strength-to-weight ratio and the excellent resistance to electrochemical corrosion of composites make them attractive materials for structural applications. In addition, composites are versatile and can be formed to any desired shape and surface texture.

Some plastic materials are molded into desired shapes without reinforcement or fillers. These types of plastics usually exhibit creep and loss in strength under long-term loading. As a result, reinforcing fibers are introduced in plastics to improve their short- and long-term behaviors, enhance mechanical properties, reduce creep and shrinkage, lower the coefficient of thermal expansion, and improve dimensional stability. Reinforcing fibers may range from very short, i.e., $1 \mathrm{~mm}(0.04 \mathrm{in}$.) to continuous fibers of indefinite length ("Structural Plastics" 1984).

Fiber composites are made of thin fibers bonded together with a resin matrix. Fibers can be oriented in any direction to enhance the strength and 
stiffness of the composite in the desired direction. The structural qualities of the composite product depend mainly on the type and amount of fibers used in the direction of measurement. The resin serves only as the bonding agent. Glass is the most common type of fiber used to reinforce composites. Glass-fiber-reinforced-plastics (GFRP) are commercially available at a fairly low cost. In general, the stress-strain relationship of GFRPs is linear to failure. The strength of certain types of GFRP exceeds that of the conventional steel, i.e., the ultimate strength of GFRP bars is reported at 1,035 MPa (150 ksi) (Pleimann 1987). However, the modulus of elasticity of this type of material is about one-fourth that of steel. This limits the application of GFRPs as the main load-carrying element in many types of structures. The GFRP plate has a lower strength, but in combination with conventional materials, plates can perform very well as can be seen from the test results of upgraded concrete beams in subsequent sections. It is noted that the modulus of elasticity of composites can be increased by about three times by using more advanced reinforcing fibers such as Kevlar or graphite.

The application of fiber composites in civil engineering - type structures has been very limited. However, composites have been used extensively in a variety of other industries such as aerospace, ship-building, automotive, chemical processing, etc., since 1944 . No major problem has arisen so far due either to environmental effects or fatigue in composite components of aircrafts in service (Hoskin and Baker 1986). Some such components have been in service more than 20 years. Other applications of composites include ship hulls as long as $25 \mathrm{~m}$ ( $80 \mathrm{ft}$ ), tank domes up to $34 \mathrm{~m}$ in diameter (110 $\mathrm{ft})$, and tanks up to $380,000 \mathrm{~L}$ in capacity $(10,000$ gal $)$.

\section{Experimental Program}

\section{Test Specimens}

Five rectangular beams (beams $\mathrm{A}$ through $\mathrm{E}$ ) and one T-beam (beam F) were tested. The cross section of rectangular beams was $455 \times 205 \mathrm{~mm}(18$ $\times 8$ in.). The flange width and thickness of the T-beam were $610 \mathrm{~mm}(24$ in.) and $75 \mathrm{~mm}(3 \mathrm{in}$.$) , respectively. The height of the T-section was 455$ $\mathrm{mm}$ (18 in.); thickness of the web was $205 \mathrm{~mm}$ ( 8 in.). Each beam was 4.88 $\mathrm{m}$ long $(16 \mathrm{ft})$ and was supported on a clear span of $4.57 \mathrm{~m}(15 \mathrm{ft})$. Fig. 2 shows the cross sections and the test setup of beams. To observe the effect of the original reinforcement ratio on the strength of upgraded beams, three different reinforcement ratios were used for the tension steel. Also, to investigate the effect of shear cracking and shear reinforcement, one beam (beam A) was underdesigned for shear, according to ACI. The remaining beams were slightly overdesigned for shear to prevent premature shear failure so the flexural behavior could be observed throughout the loading up to failure. The reinforcement details of the beams are summarized in Table 1. Beams B and D had the same longitudinal and shear reinforcement ratios. However, beam $D$ was cambered before the composite plate was bonded to its tension flange to observe the effects of external prestressing. All beams were strengthened with GFRP plates that were $152 \mathrm{~mm}$ wide ( 6 in.) by $6 \mathrm{~mm}$ thick $(0.25 \mathrm{in}$.) and $4.26 \mathrm{~m}$ long $(14 \mathrm{ft})$ and bonded to their tension flanges.

\section{Materials}

1. Concrete: Ready-mixed concrete was used for all beams. Nine $152 \times 305$ $\mathrm{mm}(6 \times 12 \mathrm{in}$. $)$ concrete cylinders were cast and tested to determine the 


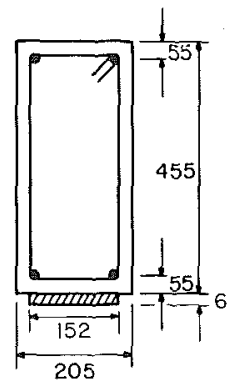

RECTANGULAR
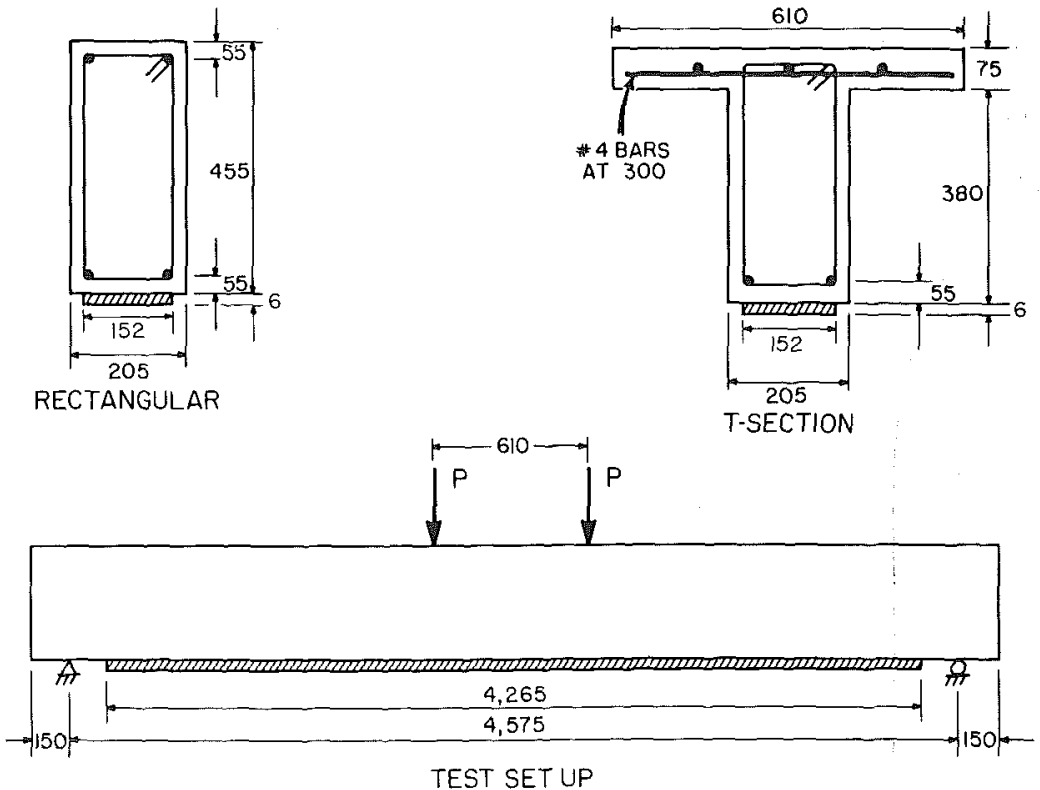

FIG. 2. Cross Sections and Test Setup of Beams

TABLE 1. Design Details of Test Specimens

\begin{tabular}{|c|c|c|c|}
\hline $\begin{array}{c}\text { Beam } \\
(1)\end{array}$ & $\begin{array}{c}\text { Compression } \\
\text { steel } \\
(2) \\
\end{array}$ & $\begin{array}{c}\text { Tension } \\
\text { steel } \\
(3)\end{array}$ & $\begin{array}{c}\text { Number } \\
\text { of stirrups } \\
(4)\end{array}$ \\
\hline A & 2 No. $4^{n}$ & 3 No. $8^{\mathrm{b}}$ & 14 No. $3^{\mathrm{c}}(\boldsymbol{a} 330 \mathrm{~mm}$ (13 in.) \\
\hline $\mathrm{B}$ & 2 No. 4 & 2 No. 8 & 34 No. $4 @ 150$ mm (6in.) \\
\hline $\mathrm{C}$ & 2 No. 4 & 2 No. 4 & 34 No. $4 @ 150 \mathrm{~mm}$ (6in.) \\
\hline $\mathrm{D}$ & 2 No. 4 & 2 No. 8 & 34 No.4@150mm (6in.) \\
\hline $\mathrm{E}$ & 2 No. 4 & - & 34 No. $4 @ 150$ mm (6 in.) \\
\hline $\mathrm{F}$ & 3 No. 4 & 2 No. 8 & 34 No.4@150mm (6in.) \\
\hline
\end{tabular}

Nominal diameter of No. 4 bar $=13 \mathrm{~mm}(1 / 2 \mathrm{in}$.$) .$

${ }^{\mathrm{b}}$ Nominal diameter of No. $8 \mathrm{bar}=25 \mathrm{~mm}(1 \mathrm{in}$.$) .$

'Nominal diameter of No. $3 \mathrm{bar}=9.5 \mathrm{~mm}(3 / 8 \mathrm{in}$.).

compressive strength of the concrete. The average compressive strength was 35 MPa $(5,040$ psi).

2. Steel: Three samples of the steel rebar were tested under uniaxial tension. The average measured yield stress of the bars was $456 \mathrm{MPa}(66.2 \mathrm{ksi})$.

3. GFRP Plate: Three samples of GFRP plate were tested under uniaxial tension. The specimens exhibited linear-elastic behavior up to failure, with an average modulus of elasticity of $37,230 \mathrm{MPa}(5,400 \mathrm{ksi})$ and an average ultimate strength of $400 \mathrm{MPa}(58 \mathrm{ksi})$.

4. Epoxy: The success of this strengthening technique is critically dependent 
on the performance of the epoxy used. Numerous types of epoxies with a wide range of mechanical properties are commercially available. To select a suitable epoxy for this particular application, several were selected and tested in a separate study (Saadatmanesh and Ehsani 1990). As a result of this study, it was concluded that tough epoxies are the most suitable for this application. An epoxy that performed very well in the earlier study was used in the test beams. This was a two-component, rubber-toughened epoxy with a consistency similar to that of cement paste. According to the data supplied by the manufacturer, the lap shear strength of the epoxy with metal substrates ranged from 14 to 15 $\mathrm{MPa}(2,000$ to $2,200 \mathrm{psi})$ with a maximum elongation at failure of $40 \%$. The required curing time of the epoxy was $4 \mathrm{hr}$ at room temperature. The manufacturer also indicated that this particular epoxy had a very good resistance to salt and moisture, and that it had originally been developed for bonding components of automobiles.

\section{Fabrication}

All beams were cast, strengthened, and tested in the Structural Engineering Laboratory of the University of Arizona. After the beams were cured for at least 28 days, the tension face of each beam was sandblasted down to aggregate. The surfaces of plates were cleaned with a diluted acid and then neutralized before bonding. Next, a layer of epoxy was applied on the tension face of each beam and the plate was placed on the epoxy. Because of the uneven surface of the concrete after sand blasting, it was difficult to maintain a perfectly uniform epoxy thickness throughout the length of the beam. However, on the average, the epoxy thickness was about $1.5 \mathrm{~mm}(1 / 16 \mathrm{in}$.).

\section{Instrumentation}

The strains in the concrete, steel rebars, and plastic plate in the section at midspan of each beam were measured by electric resistance strain gages. For measuring the steel strain, two strain gages were mounted diametrically opposed on each tension rebar. The concrete strain was measured by means of three $76-\mathrm{mm}$-long ( $3 \mathrm{in}$.), electric resistance strain gages placed on the compression face of each beam. For measuring the plate strain, two gages were placed on the plate surface at midspan. Deflection was measured by means of two LVDTs placed on the top face of the beam at midspan. Load was measured by a load cell. The averages of measured strains and deflections were used in the analysis of data.

\section{Test Procedure}

All beams were simply supported on a clear span of $4.57 \mathrm{~m}(15 \mathrm{ft})$, and they were subjected to two concentrated loads symmetrically placed about the midspan. The loading points were $0.61 \mathrm{~m}(2 \mathrm{ft})$ apart. The beams were incrementally loaded to failure. After each increment of the load, the strains in the concrete, steel rebars, plastic plate, and the deflection at midspan were measured by means of an automatic data acquisition system. The same loading rate was used for all beams.

\section{Test Results}

The measured load versus deflection and the load versus strain in concrete, steel rebar, and GFRP plate are discussed in the following for each beam. In addition to the measured curves shown with solid lines in subsequent 
figures, two other curves are shown on each figure. The dashed curve represents the predicted (calculated) behavior of the strengthened beams; the dotted curve represents the predicted response of the same beam if no plate had been attached to it. The predicted curves are generated using a computer program based on analytical models discussed in the companion paper (An et al., 1991). All calculated curves were terminated when strain in concrete in the compression face of the beam reached 0.003 .

\section{Beam A}

This beam was reinforced with three no. 8 tension bars and two no. 4 compression rebars. Fig. 3( $a$ ) shows the measured and calculated load versus deflection curves of beam $\mathrm{A}$. The calculated load versus deflection response of beam A with no plate is also shown on the same figure. The predicted and measured results correlated well in the elastic region and at the ultimate load. The difference between the two curves in the intermediate region
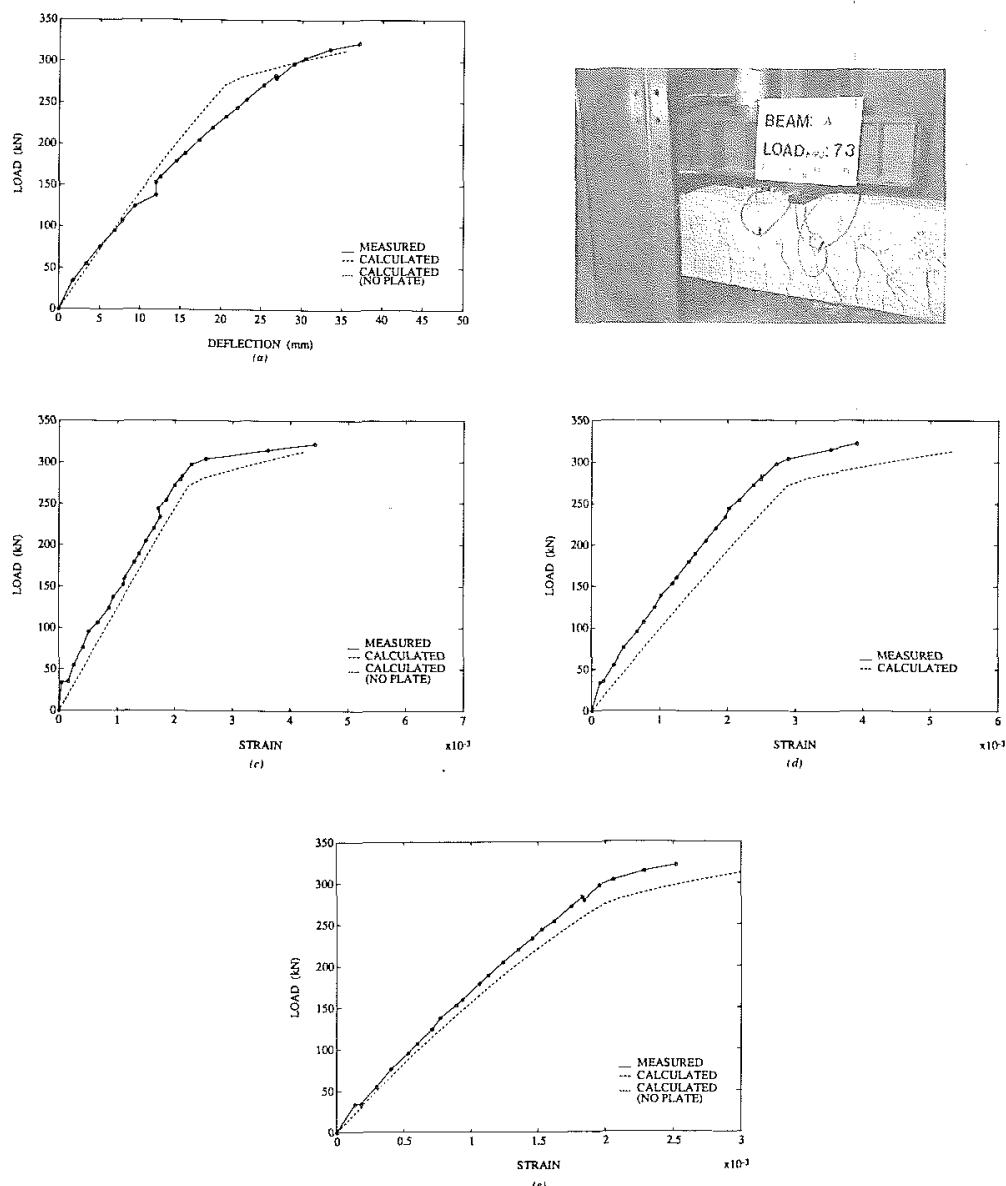

FIG. 3. Plots of: (a) Load versus Deflection; (b) Beam at Failure. Load versus Strain in: (c) Steel Rebar; (d) GFRP Plate; (e) Concrete at Midspan of Beam A 
could be attributed to slip and imperfect composite action at the bond line between the plate and concrete, which were not included in the analytical models. Comparison of the solid and dotted curves shows the gain in the stiffness and ultimate capacity as a result of plating. Even though this beam was slightly underdesigned for shear, no major shear cracks or shear failure were observed throughout the loading. Fig. 3(b) shows beam A at failure. The failure was reached as a result of crushing of concrete in compression.

Fig. 3(c) shows the measured and predicted load versus strain in the steel rebars. The strain in the rebars increased at a higher rate after concrete cracked at a load of $35 \mathrm{kN}$ ( $8 \mathrm{kips}$ ). The strains then increased almost linearly until the rebars yielded at a load of $300 \mathrm{kN}$ (67 kips). A comparison of the dotted and solid curves indicates that plating increased the yield load by about $33 \%$.

The measured and calculated load versus strain curves in the GFRP plate are shown in Fig. 3(d). Load-strain behavior similar to that for the rebars was observed in the GFRP plate. The strain in the rebars increased at a higher rate after the concrete cracked at a load of $35 \mathrm{kN}$ ( $8 \mathrm{kips}$ ). The loadstrain curve then continued linearly until the rebars yielded at a load of 300 $\mathrm{kN}$ (67 kips). At this load, the strain in the plate increased at a much faster rate, indicating that the composite plate alone resisted further increments of the tensile component of the internal moment couple after the rebars yielded. The slopes of the measured and predicted curves correlate very well, indicating that the analytical models predict the stresses in the plate reasonably well. The difference between the two curves results partially from the initial offset as a result of the assumption of zero tensile strength in concrete.

Fig. 3(e) shows the measured and predicted load versus strain in concrete throughout the loading to failure. The measured curve is shown with the solid line. The stiffness of the beam reduced after concrete cracked at a load of $35 \mathrm{kN}$ ( $8 \mathrm{kips}$ ), resulting in larger strains. In the analytical models, the tensile strength of concrete was ignored. Therefore, this sudden change in stiffness is not shown on the predicted curves. The small difference between the measured and predicted curves is mainly due to the initial offset in the predicted curve that resulted from ignoring the tensile strength of the concrete in the analytical models.

\section{Beam B}

The measured and predicted load versus deflection curves of beam $B$ are shown in Fig. 4(a). The measured results show a reduction in stiffness after concrete cracked at a load of $49 \mathrm{kN}$ (11 kips). The steel rebars yielded at $185 \mathrm{kN}$ (41.6 kips). At this point, the stiffness of the beam further reduced; however, the beam could still carry additional loads, and the behavior continued almost linearly until the ultimate failure was reached at a load of 250 $\mathrm{kN}$ (56.2 kips). The failure was caused by debonding of the composite plate and the beam just before reaching the crushing load of concrete. The debonding occurred suddenly and in a brittle manner; however, there was no major damage in the beam, and the beam could still carry load after debonding of the plate. Fig. $4(b)$ shows the beam at the conclusion of the test. A comparison of the measured and predicted curves indicates that the measured and calculated yield and ultimate loads are reasonably close. The small difference in the measured and calculated loads is due to the imperfect composite action at the plate-concrete interface. The difference at the ultimate load results from the premature debonding of the plate and concrete. 

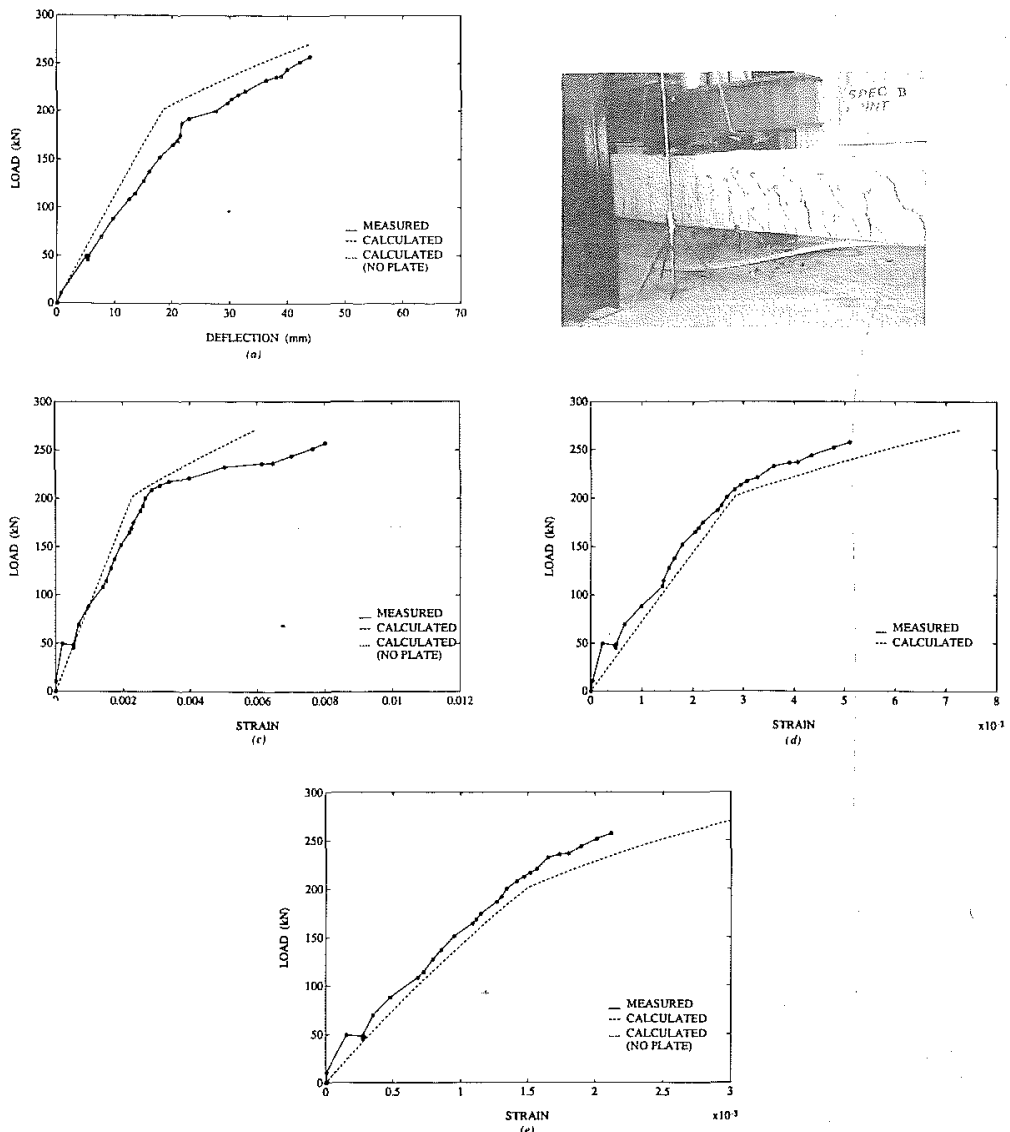

FIG. 4. Plots of: (a) Load versus Deflection; (b) Beam at Failure. Load versus Strain in: (c) Steel Rebar; (d) GFRP Plate; (e) Concrete at Midspan of Beam B

Comparing the curves for the strengthened beam and that for the beam with no plate indicates that plating increased the yield and ultimate loads by about $15 \%$ and $65 \%$, respectively. In addition, after steel rebars yielded, no significant increase in the load can be observed for the beam with no plate.

Fig. 4(c) shows the measured and predicted load versus strain curves in the steel rebars. After concrete cracked at $49 \mathrm{kN}$ (11 kips), the strain in the steel rebars increased and the stiffness of the beam reduced. After cracking, the measured values of strains are higher than the calculated values. This is because of the lower stiffness of the beam caused by relative slip of the plate and concrete at the bond line. By comparing the solid and dotted curves, it can be seen that plating increased the load at which the steel rebars yielded. Fig. $4(d)$ shows the measured and calculated load versus strain in the composite plate. After cracking of concrete, the strain in the plate increased at a higher rate. The behavior continued almost linearly until the steel rebars 
yielded. At this point, the strains in the composite plate increased at a significantly higher rate, indicating that the plate alone carried the increments of the tensile component of the internal moment. Fig. 4(e) shows the load versus strain curves in the compression face of concrete at midspan.

\section{Beam C}

The composite plate for this beam was bonded while the beam was held cambered. To simplify the cambering operation, the beam was loaded upside down in loose contact with an epoxy-coated composite plate. The load was applied through two concentrated load points placed symmetrically about the midspan, $305 \mathrm{~mm}$ (12 in.) apart. The beam was held in this position until the epoxy completely cured. It was then turned right-side up and was placed in the test frame. The steel reinforcement in this beam consisted of two no. 4 tension rebars and two no. 4 compression rebars. As a result, a relatively small cambering force, i.e., $36 \mathrm{kN}$ ( $8 \mathrm{kips}$ ), could be applied without severely damaging the beam. In field applications, a larger cambering force can be applied because of the action of the weight of the deck. For example, the cambering force can be selected to reduce or eliminate the dead load stresses.

Fig. 5(a) shows the load versus deflection curves at the midspan of the beam. The initial negative deflection indicates the initial camber in the beam after jacks were removed and the beam was turned right-side up. The beam was loaded to $107 \mathrm{kN}$ (24 kips); it was then unloaded and reloaded. The unload-reload segment exhibited a small hysteresis loop. The loading was then continued until the beam failed as a result of sudden failure of concrete between the plate and longitudinal steel rebars as shown in Fig. 5(b). This mode of failure also has been observed in beams strengthened with epoxybonded steel plates (Swamy et al. 1987). The measured and predicted loaddeflection curves correlated well. This was mainly because of a better bond behavior, compared with the previous beams. The load-deflection curve of the same beam but with no plate is shown in Fig. 5(a) with dotted lines. As can be seen from the figure, plating significantly increased the yield and ultimate loads of the beam. Because the beam originally had a relatively small amount of reinforcement, the concrete in the beam could not be utilized efficiently. However, by adding a moment couple, consisting of the tension force in the composite plate and an equal compression force in the concrete, the ultimate capacity of the beam was substantially increased.

The load versus strain in steel rebars is shown in Fig. 5(c). In the elastic region, the agreement between the measured and calculated strains was good. In the inelastic region, the difference between the two curves can be attributed to opening of cracks and local debonding of steel and concrete. Fig. $5(d)$ shows the load versus strain in the GFRP plate. The strain in the composite plate increased almost linearly until the rebars yielded at a load of about $100 \mathrm{kN}(22.5 \mathrm{kips})$. At this point, the strain in the plate increased at a faster rate, indicating that the plate alone resisted the tensile component of the internal moment couple for further increases of the applied load. The calculated load versus strain in the plate is shown on the same figure with dashed lines. The measured strains are smaller than the calculated values. This is because of the relative slip between the plate and the beam, which was not included in the analytical models.

Fig. 5(e) shows the load versus strain in the extreme compression fiber of concrete. The measured strain at which the beam failed is smaller than the calculated one, the reason being that the beams did not fail by crushing 

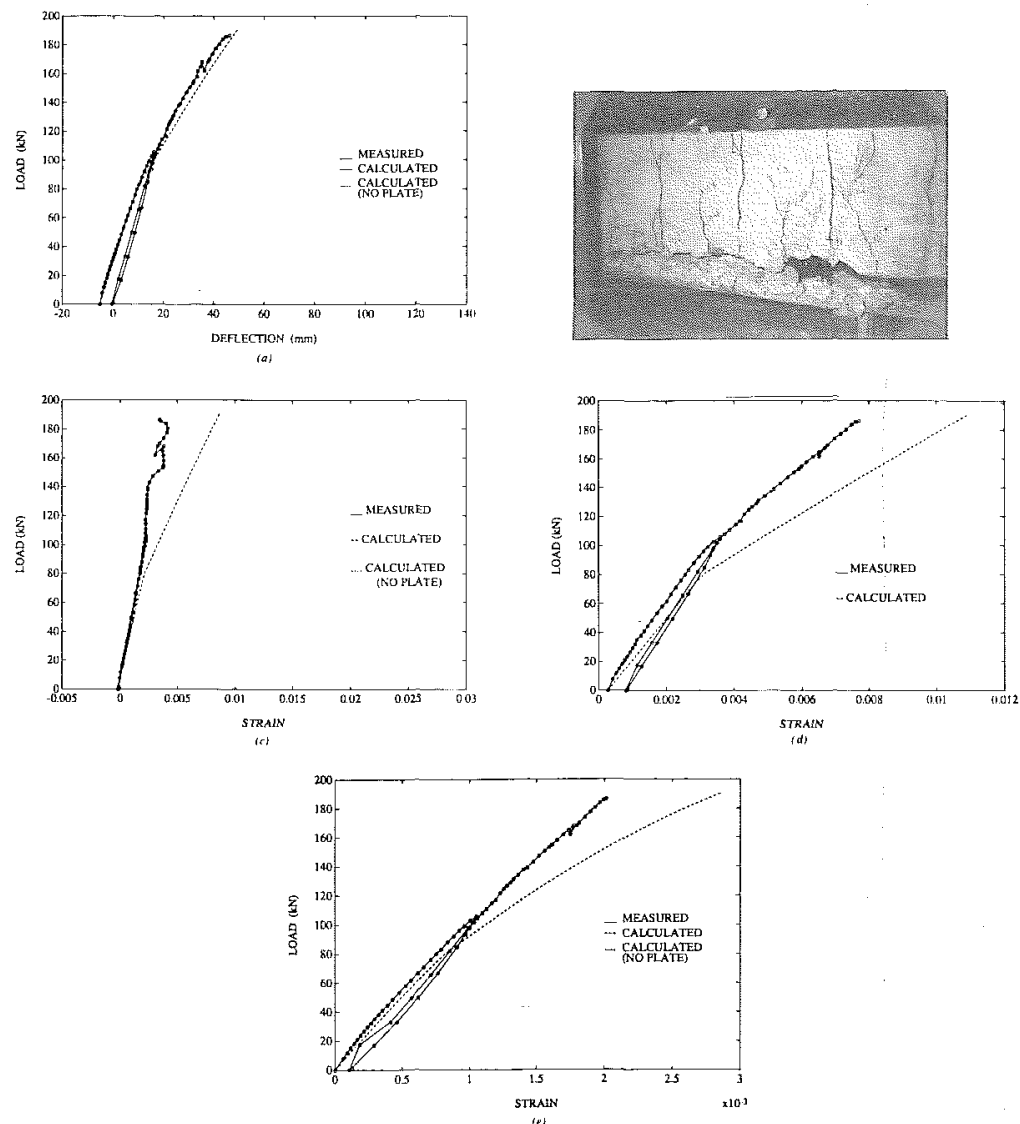

FIG. 5. Plots of: (a) Load versus Deflection; (b) Beam at Failure. Load versus Strain in: (c) Steel Rebar; (d) GFRP Plate; (e) Concrete at Midspan of Beam C

of concrete, but by shear failure of the concrete layer between the plate and rebars [Fig. 5(b)].

\section{Beam D}

This beam had the same design parameters as those for beam $C$, except it had two no. 8 bars for tension reinforcement. Beam $\mathrm{D}$ was also cambered in the same manner as beam $C$. This beam had been precracked prior to bonding of the composite plate. Cambering partially closed some of the cracks. The measured and predicted load versus deflection curves of beam $\mathrm{D}$ are shown in Fig. 6(a). The initial offset indicates the camber remained in the beam after the jacks were removed. Because this beam had been precracked, the load-deflection curve did not exhibit a reduction in stiffness as a result of cracking of concrete. In the elastic range of loading, the measured deflections shown by the solid line were larger than the calculated values shown by the dashed lines. This can be attributed to the imperfect 

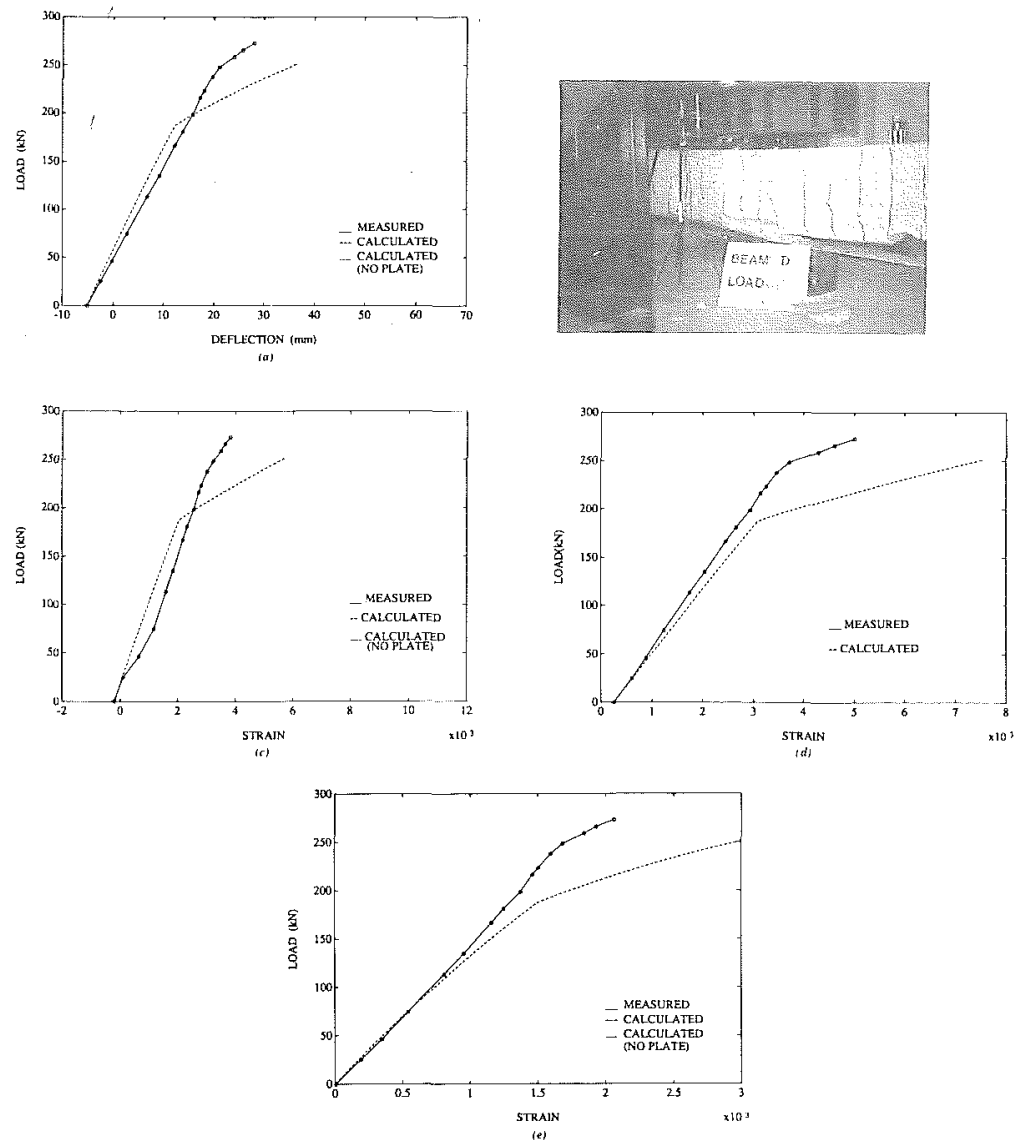

FIG. 6. Plots of: (a) Load versus Deflection; (b) Beam at Failure. Load versus Strain in: (c) Steel Rebar; (d) GFRP Plate; (e) Concrete at Midspan of Beam D

composite action of the plate and concrete beam. In the inelastic range, the measured deflections are smaller. This can result from higher actual rebar yield stress than the value assumed in the calculations and also to strainhardening of rebar. By comparing the curves for the beam with plate and those for the beam without plate, it can be seen that the gain in the ultimate capacity is not as significant as that for beam $C$. This is because of the higher steel reinforcement ratio of beam $D$. The beam failed as a result of the sudden failure of the concrete layer between the plate and rebars, as shown in Fig. 6(b).

The load versus strain in the rebars and plastic plate are shown in Figs. $6(c)$ and $6(d)$, respectively. The initial offsets in the curves indicate the strains in the bars and plate due to cambering. The calculated strains in the rebars are smaller than the measured values; the calculated strains in the composite plate are slightly larger than the measured values. The differences between the measured and calculated values can be explained by the im- 
perfect composite action of the plate and concrete and by the relative slip at the bond line. This phenomenon relieves the plate from carrying its full theoretical load and, consequently, the rebars must carry an additional load.

Fig. 6(e) shows the load versus strain in the extreme compression fiber of concrete. In the elastic range, the measured and predicted values correlated well. The measured strain at the failure load of the beam is smaller than the calculated value. This is because of the failure of the beam caused by shear failure of the concrete layer below the reinforcing bars, rather than the crushing of concrete in compression, which was assumed in the analytical models.

\section{Beam E}

This beam had no longitudinal steel, but shear reinforcement was provided at a spacing of $150 \mathrm{~mm}$ ( 6 in.) (Table 1 ). The beam was reinforced only with the composite plate externally bonded to the tension flange.

Fig. 7(a) shows the load versus deflection to failure of beam E. The measured ultimate load was significantly lower than the calculated load because of premature failure of the beam caused by large tension cracks, as shown in Fig. 7(b). Plating only slightly increased the load-carrying capacity of the beam. It was concluded that a certain amount of reinforcement would be necessary to limit the width of the tension cracks and to prevent a premature bond failure.

Fig. 7(c) shows the load versus strain in the composite plate at midspan. The measured strains were smaller than the calculated values because of significant slip at the bond line caused by large crack openings. Fig. $7(d)$ shows the load versus strain in the extreme fiber of concrete in compression. The concrete did not reach its compressive strength because the beam failed
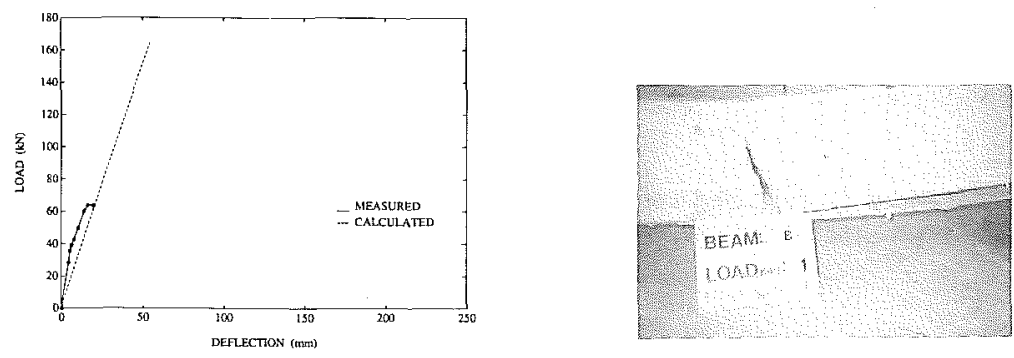

(a)
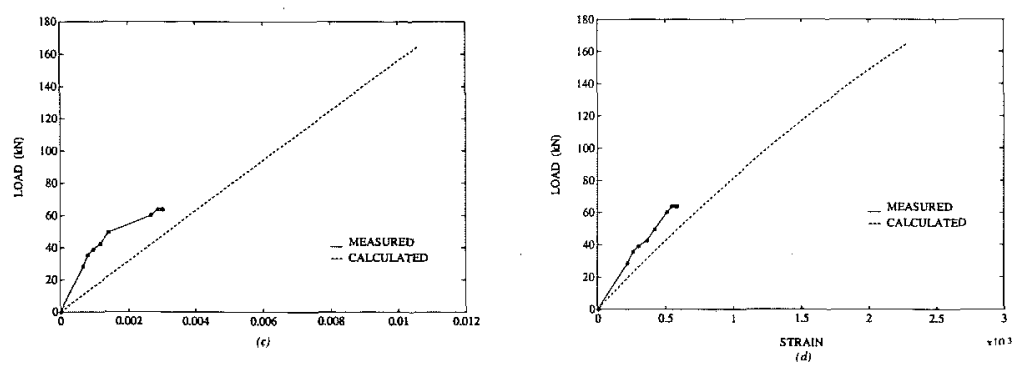

FIG. 7. Plots of: (a) Load versus Deflection; (b) Beam at Failure. Load versus Strain in: (c) GFRP Plate; (d) Concrete at Midspan of Beam E 
at a load that corresponded to a concrete strain well below the crushing strain.

\section{Beam F (T-Beam)}

This beam consisted of a $610 \mathrm{~mm}(24 \mathrm{in}$.) wide by $75 \mathrm{~mm} \mathrm{(3} \mathrm{in.)} \mathrm{thick}$ flange connected to a $455 \mathrm{~mm}$ (18 in.) high by $205 \mathrm{~mm}$ ( $8 \mathrm{in}$.) wide web. The number and size of the reinforcements in the beam are given in Table 1 . The composite plate was bonded to the tension flange with no camber.

Fig. 8(a) shows the measured and predicted load versus deflection at the midspan of the beam. Plating almost doubled the capacity of the beam, as can be seen by comparing the curves for beam without plate with that for the beam with plate. The measured and predicted curves correlated well throughout, except at the ultimate load. The reason for this difference was the sudden premature separation of the plate and the beam, perhaps re-
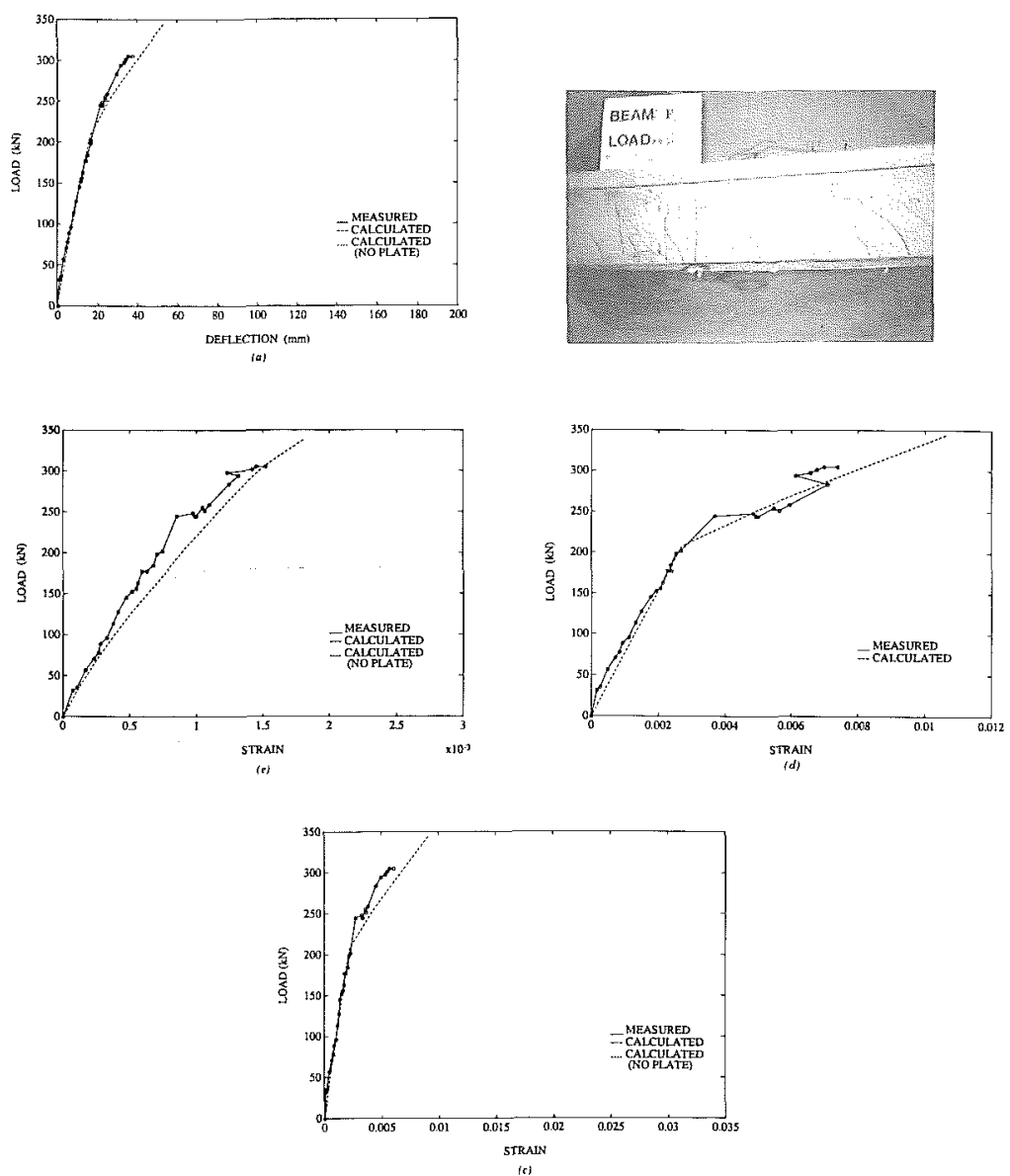

FIG. 8. Plots of: (a) Load versus Deflection; (b) Beam at Failure. Load versus Strain in: (c) Steel Rebar; (d) GFRP Plate; (e) Concrete at Midspan of T-beam (Beam F) 
sulting from poor workmanship in surface preparation and bonding. The loading was stopped at this point. Fig. $8(b)$ shows the beam at failure when the plate separated from the beam.

The load versus strain in steel rebars and GFRP plate are shown in Figs. $8(c)$ and $8(d)$, respectively. The measured and predicted values correlate reasonably well. At a measured load of $250 \mathrm{kN}$ ( $56.2 \mathrm{kips}$ ), the rebars yielded, resulting in a reduced stiffness. At the same time, the additional increments in the tensile load of rebars transferred to the GFRP plate, as can be seen by the sudden increase in the plate strain [Fig. 8(d)]. Fig. 8(e) shows the load versus strain in the top concrete fiber at midspan. At a load of about $35 \mathrm{kN}$ ( $7.9 \mathrm{kips})$, the concrete cracked, resulting in reduction of the beam stiffness. Comparing the strains for the beam with plate and those for the beam without plate, it can be seen that plating reduced the strain in the concrete for all load levels.

\section{Conclusions}

The results of tests performed in this study indicate that significant increase in the flexural strength can be achieved by bonding GFRP plates to the tension face of reinforced concrete beams. The gain in the ultimate flexural strength was more significant in beams with lower steel reinforcement ratios. In addition, plating reduced crack size in the beams at all load levels. The successful application of this technique requires a careful preparation of concrete surface and the selection of a tough epoxy. Plating somewhat reduced the ductility of the beams. This reduction in ductility varies with the ductility of the original beam and must be considered in the design. A comparison of the measured results and analytical results based on the equilibrium of forces and compatibility of deformations indicated that the behavior of upgraded beams can be predicted with reasonable accuracy. However, additional analytical and experimental studies must be undertaken to establish criteria for predicting the limiting load that causes the concrete layer between the longitudinal rebars and plate to fail. Cambering the beams resulted in improved cracking behavior, but before field application, further studies must be conducted to examine the creep behavior of the epoxy joint subjected to sustained cambering stresses. In addition, the effects of environmental factors, e.g., temperature and moisture on the epoxy joint, as well as the performance of upgraded beams under fatigue loading should be examined.

\section{Appendix I. References}

An, W., Saadatmanesh, H., and Ehsani, M. R. (1991). "R/C beams strengthened with FRP plate. II: Analysis and parametric study." J. Struct. Engrg., ASCE, $117(11)$.

"Araldit for a bridge: Bonded reinforcing instead of replacement." (1979). CibaGeigy, Aspekte, Switzerland, 4, 2-4.

Dussek, I. J. (1980). "Strengthening of bridge beams and similar structures by means of epoxy-resin-bonded external reinforcement," Transport. Res. Rec. 785, Transportation Research Board, 21-24.

"Highway bridge replacement and rehabilitation program." (1989). 10th Annual Report of the Secretary of Transportation to the Congress of the United States, Bridge Division, Office of Engineering, Federal Highway Administration, Washington, D.C.

Hoskin, C. B., and Baker, A. A. (1986). Composite materials for aircraft structures. AIAA Education Series, American Institute of Aeronautics and Astronautics, Inc., New York, N.Y. 
Klaiber, F. W., Dunker, K. F., and Sanders, W. W. (1982). "Strengthening of singlespan steel beam bridges." J. Struct. Engrg., ASCE, 108(12), 2766-2780.

Klaiber, F. W., Dunker, K. F., Wipf, T. J., and Sanders, W. W., Jr. (1987). "Methods of strengthening existing highway bridges." Report No. 293, National Cooperative Highway Research Program.

Lloyd, G. D., and Calder, A. J. J. (1982). "The microstructure of epoxy bonded steel-to-concrete joints." Supplemental Report No. 705, Transport and Road Research Laboratory, Structures Department, Bridge Division, Crowthorne, Berkshire, England.

MacDonald, M. D., and Calder, A. J. J. (1982), "Bonded steel plating for strengthening concrete structures." Int. J. Adhes. Adhes., 2(2), 119-127.

Pleimann, L. G. (1987). Tension and bond pull-out tests of deformed fiberglass rods. Vega Technologies, Marshal, Ark.

Raithby, K. D. (1980). "External strengthening of concrete bridges with bonded steel plates." Report No. SR 612, Department of Transportation, Transport and Road Research Laboratory, Crowthorne, Berkshire, England.

Saadatmanesh, H., Albrecht, P., and Ayyub, B. M. (1989a). "Experimental study of prestressed composite beams." J. Struct. Engrg., ASCE, 115(9), 2349-2364.

Saadatmanesh, H., Albrecht, P., and Ayyub, B. M. (1989b). "Analytical study of prestressed composite beams." J. Struct. Engrg., ASCE, 115(9), 2365-2382.

Saadatmanesh, H., Albrecht, P., and Ayyub, B. M. (1989c). "Guidelines for Flexural Design of prestressed composite beams." J. Struct. Engrg., ASCE, 115(11), 29442961 .

Saadatmanesh, H., and Ehsani, M. R. (1990). "Fiber composite plates can strengthen concrete beams." Concr. Int., ACI, 12(3), 65-71.

"Structural plastics design manual." (1984). Manual No. 63, ASCE Manuals and Reports on Engineering Practice, ASCE, New York, N.Y.

Swamy, R. M., Jones, R., and Bloxham, J. W. (1987). "Structural behavior of reinforced concrete beams strengthened by epoxy-bonded steel plates." The Struct. Eng., 65A(2), 59-68.

VanGemert, D. A., and VandenBosch, M. C. J. (1985). "Repair and strengthening of reinforced concrete structures by means of epoxy bonded steel plates." Int. Conf. on Deterioration, Bahrain, 181-192. 